\title{
MULTI-SOURCE APPROACHES FOR COMPLEX ARCHITECTURE DOCUMENTATION: THE "PALAZZO DUCALE" IN GUBBIO (PERUGIA, ITALY)
}

\author{
G. Patrucco ${ }^{1}$, F. Rinaudo ${ }^{1}$, A. Spreafico ${ }^{1, *}$ \\ DAD, Department of Architecture and Design, Politecnico di Torino, Viale Mattioli 39, 10125 Torino \\ (giacomo.patrucco, fulvio.rinaudo, alessandra.spreafico)@ polito.it
}

Commission II, WG II/8

KEY WORDS: SLAM, LiDAR, UAV photogrammetry, point clouds, Cultural Heritage documentation

\begin{abstract}
:
Nowadays, the employment of rapid mapping solutions for architectural survey is more and more considered, not only for the strong reduction of the primary data acquisition times, but also thanks to their adaptability to various contexts, especially in the framework of Cultural Heritage documentation where tailored solutions are required. The combined use of Mobile Mapping Systems (MMS), Unmanned Aerial Vehicles (UAV) for close range aerial image acquisition, and Terrestrial Laser Scanning (TLS) seems to be an effective solution for the architectonic scale compliant to the level of detail and accuracy of 1:200, and 1:100 scales. The present research tries to evaluate the use of a handheld MMS, the ZEB-Revo RT by Geoslam, an UAV, the DJI Mavic Pro, and a LiDAR system, the Faro Focus ${ }^{3 D}$ S 120 by CAM2. The complex case of the documentation metric survey of Palazzo Ducale in Gubbio, the Montefeltro's Palace, now hosting the museum of itself, allows the comparison of the effectiveness of the used technologies.
\end{abstract}

\section{INTRODUCTION}

Historical complexes constitute a challenge for documentation, conservation, and understanding purposes also referring to policies of museum management in which a reliable 3D model plays a crucial role for different investigations and uses. In the last few years, the development of newest technologies in the framework of Mobile Mapping System (MMS) is providing a valid and growing contribution to 3D metric documentation of built heritage beside the well-known capabilities of Terrestrial Laser Scanning (TLS) and automatic digital photogrammetry. Among the various type of MMS, devices based on Simultaneous Localization And Mapping (SLAM) algorithms are increasingly used by many users operating in the field of Geomatics (di Filippo et al., 2018; Sammartano \& Spanò, 2018). SLAM based instruments solve the positioning problem without Global Navigation Satellite System (GNSS) help, and collect data in every kind of contexts also with a very high level of complexity; the flexibility of handheld solution makes SLAM based sensors suitable and competitive for Cultural Heritage documentation (Chiabrando et al., 2019; Mandelli et al., 2017). Furthermore, SLAM-based data can be integrated with point clouds acquired by Laser Scanning devices or extracted from images thanks to automatic digital photogrammetry. The employment of Unmanned Aerial Vehicle (UAV) is certainly a growing solution to obtain the aerial point of view (Crommelinck et al., 2016; Hardin et al., 2019) and its integration with SLAM-based sensors is hereby evaluated as complementary solutions to rapidly map architectural complexes. The use of a multi-sensor derived data integration approach is nowadays largely employed in the framework of Cultural Heritage documentation and allows to achieve greater adaptability as far as 3D metric acquisition in different scenarios is concerned (Chiabrando et al., 2019; G. Tucci et al., 2017). By considering the goals of the survey, a careful

\footnotetext{
* Corresponding author
}

consideration to understand which are the most convenient and effective sensors and approaches is necessary to achieve the more suitable results also considering aspects such as costs, time, and circumstances showed by complex buildings. One of the factors to be considered is the different accuracies of data coming from different technologies, which drive the possible solution towards a multi-scale 3D model.

\section{CASE STUDY: THE PALAZZO DUCALE IN GUBBIO}

The case study analysed in this paper is "Palazzo Ducale" of Gubbio, a valuable example of Renaissance architecture built on pre-existing structures. The events linked to the phases of construction of the Palace and their dating, mostly referring to the most important Renaissance period, are yet theme of debate and are well documented and discussed (Capannelli \& Sannipoli, 2008). The Palace certainly grew up on previous buildings property of the city of Gubbio and donated in 1480 to the Montefeltro family, lords of Gubbio during the XIV and XV centuries. The design of the Renaissance Palace is probably due to Francesco di Giorgio Martini on the basis of Luciano Laurana's drawings for Federico Montefeltro as the "minor brother" of the Palazzo Ducale of Urbino. Gubbio was the vacation residence, while Urbino was the main one of the Montefeltro family, but it is supposed that the same artisans worked for both the Palaces, circumstance that can explain the similarities between the Palace of Gubbio and the Palace of Urbino. Constructed near the city centre in appearances similar to the other buildings, the Ducal Palace of Gubbio arise in a predominant position on the city and in the shadows of Ingino Mount. The Palace is in between the Cathedral and the Consoli Palace, symbols of religious and political power, creating articulated and uneasy to access streets and influencing an irregular composition of the architectural planning. The actual complex encloses several building made of brick, sandstone and 
limestone in the Renaissance aspect (Figure 1): the ancient street with the medieval Palace (also called "Palazzo Vecchio" or Palatium) now open spaces; a medieval tower transformed into the tank of the old city's water supply; the public Palace (called "Palazzo della Guardia") dated back to the XIII century and part of the new Federico's Palace; the vaulted street in the lower part between the garden and the double level of underground. Three stairs (the spiral stair for service, the honour stairway, and the newest one) connect all the parts of the complex divided in five levels: two undergrounds, the main and first floor as noble apartments, the new mezzanine floor.

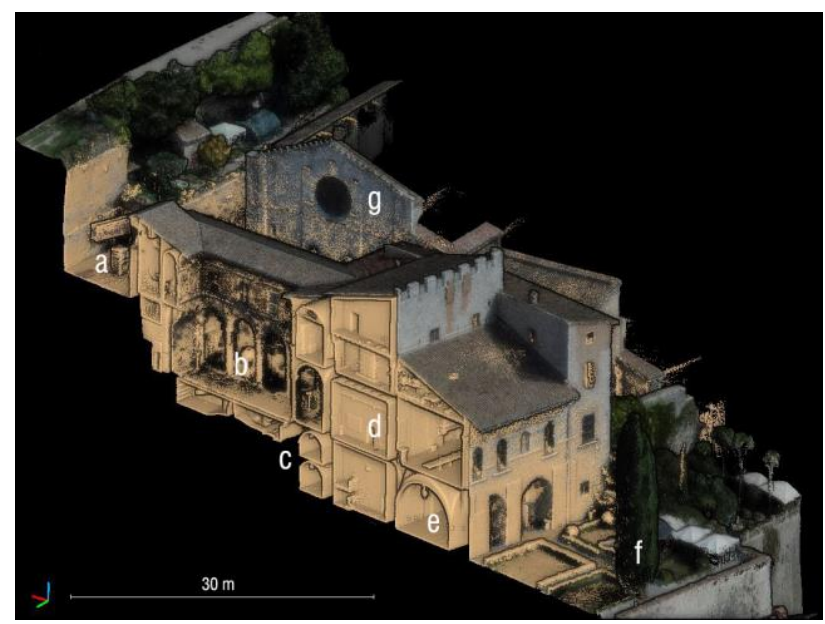

Figure 1. Composition of the complex of "Palazzo Ducale": (a) "Palazzo Vecchio", (b) courtyard, (c) double level of underground, (d) main floor and upper levels, (e) passage of the street, (f) garden, (g) façade of the Cathedral facing the main entrance of the palace.

The courtyard constitute the core of the entire complex, in fact it is built on the ancient square of the Cathedral, connecting the existing buildings and the new parts of the Palace: its shapes are similar to those of the Urbino's courtyard. The rhythmic repetition of cross vaults and columns, supporting round arches and surmounted by circles, regularises three sides of the trapezoidal profile at the ground floor, while the fourth presents small arches supporting the cantilever upper part. Grey stone semi-columns with frieze as frame for the rectangular windows and red brick walls compose the first floor. Everywhere in the Palace the coat of arm with the inscription "FE DUX" appears, recalling the Duke Federico as the owner. This decoration is particularly important where inserted on the square brick called "formella" because it represents the "piede urbinate", the length unit of measurement of that time, corresponding to $0.335 \mathrm{~m}$, that was used as unit of dimensions of the entire building.

Nowadays the Palace hosts temporary and permanent exhibitions, despite being almost devoid of the Federico's furniture is a museum of itself with regard not only to the most notorious architecture of Federico from Montefeltro, but also to the archaeological excavations of the so-called "Palazzo Vecchio" and of medieval remains in the underground. Several drawings due to metric survey or archaeological excavations reports the state of the entire Palace or a part of itself over the years $(1631,1883,1930,1987,2003)$. Nonetheless, until now, some areas of the palace had not yet metrically documented (e.g. the Palazzo Vecchio that has been the object of an interesting archaeological campaign of analysis), all the existing surveys are documented by means of traditional 2D drawings: furthermore, a digital 3D model does not exist.

\section{DATA ACQUISITION}

During September 2018 a team of the Politecnico di Torino performed a multi-sensor survey (image and range based); the main aim is to obtain a multiscale 3D metric documentation of the entire built asset (Scolamiero, 2019). A Light Detection and Ranging (LiDAR) survey has been executed inside and outside of the upper parts of the building; multiple scans were acquired with a Time of Flight (ToF) laser scanner. In addition, a UAV based photogrammetric survey has been carried out, focusing on external areas of the whole Palazzo Ducale, the rooftops, and the external facades of the building. Due to the limited space in front of the exterior facades the Laser scanner survey was not used for the upper parts of them. Furthermore, the entire Palazzo has been mapped testing a MMS. The coordinate system, where all the collected data are referred to, has been fixed by means of traditional topographic methods.

\subsection{UAV photogrammetry: the Mavic Pro}

The use of aerial photogrammetry for documentation of Cultural Heritage is becoming more and more frequent, especially as regards contexts of high extension and complexity (Lo Brutto et al., 2014; Sauerbier \& Eisenbeiss, 2010) as the one presented in this paper. Nowadays the market is adjusting in order to answer to this kind of demands and it is offering an increasing number of solutions useful not only for close range aerial image acquisition but also for vertical surface surveys. Commercial drones represent an effective and low-cost solution for images acquisition from unusual and hard to reach prospective (Hardin et al., 2019). Also in the case presented in this paper a UAV photogrammetric survey has been carried out using a drone to cover the areas of the rooftops and the higher parts of the facades of the Palazzo Ducale. The employed system is a Mavic Pro (Figure 2), a drone developed by DJI (Dà-Jiāng Innovations Science and Technology Co., Ltd) equipped with a DJI FC220 camera mounted on a 3-axis gimbal (Table 1).

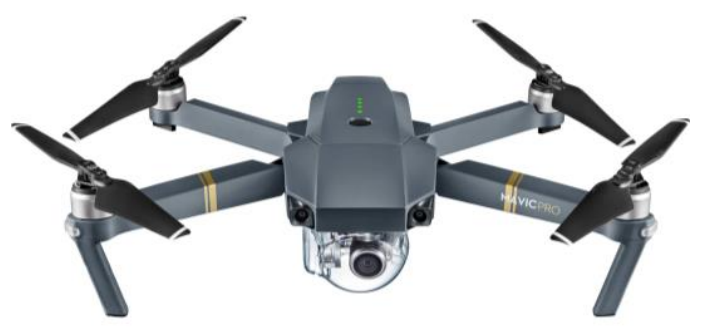

Figure 2. DJI Mavic Pro.

To obtain a common coordinate system for all the measurements carried out during the survey, a topographic control and second order networks have been realized using a total station.

\begin{tabular}{|c|c|}
\hline Specifications & Mavic Pro \\
\hline Camera model & DJI FC220 \\
\hline Sensor & CMOS 7.66 x 6.17 mm \\
\hline Effective pixels & $12 \mathrm{Mpixels}$ \\
\hline Lens & $\begin{array}{c}\text { FOV } 78.8^{\circ} 5 \mathrm{~mm} \mathrm{f} / 2.2(26 \mathrm{~mm} \\
\text { in } 35 \mathrm{~mm} \text { format equivalent })\end{array}$ \\
\hline ISO Range & $100-1600$ \\
\hline Shutter Speed & $8 \mathrm{~s}-1 / 8000 \mathrm{~s}$ \\
\hline Max image size & $4000 \times 3000$ pixels \\
\hline Photo format & JPG, DNG \\
\hline
\end{tabular}

Table 1. DJI Mavic Pro principal specifications. 
Artificial markers have been placed on horizontal and vertical surfaces of Palazzo Ducale; from the vertexes of the control network, these targets have been measured to obtain ground control points to ease the registration of different point clouds and, part of them, used as check point to assess the accuracy of the final point cloud of the whole building.

Four flights (Table 2) have been carried out with the camera configured in three different ways (nadiral, oblique and forward) to collect data of the selected outer surfaces of the Palazzo (Table 2 number 1-3). Images collected during the first three flights constitute the complete dataset of the entire complex (527 images). The flight planning has been planned with Pix4D Capture app in order to reach a complete and correct stereoscopic coverage of the entire area. During first and second flight, several photogrammetric strips have been performed with nadiral and oblique camera configuration. The route of the third flight was circular with oblique camera configuration. The area covered by the first three flights is approximately about $0.07 \mathrm{~km}^{2}$. The fourth flight (Table 2 number 4) has been carried out in manual mode from a reduced shooting distance (around 16 metres) to obtain detailed images of the southwest façade of the Palazzo, the one facing the garden.

\begin{tabular}{|c|c|c|l|c|c|}
\hline Flight & $\begin{array}{c}\mathrm{N}^{\circ} \text { of } \\
\text { images }\end{array}$ & $\begin{array}{c}\text { Type of } \\
\text { flight }\end{array}$ & $\begin{array}{c}\text { Camera } \\
\text { config. }\end{array}$ & $\begin{array}{c}\text { Shooting } \\
\text { distance }[\mathrm{m}]\end{array}$ & $\begin{array}{c}\text { Time } \\
{[\mathrm{min}]}\end{array}$ \\
\hline 1 & 261 & $\begin{array}{c}\text { Double grid } \\
\text { (planned) }\end{array}$ & Nadiral & $\approx 68$ & 17 \\
\hline 2 & 234 & $\begin{array}{c}\text { Double grid } \\
\text { (planned) }\end{array}$ & Oblique & $\approx 68$ & 12 \\
\hline 3 & 32 & $\begin{array}{c}\text { Circular } \\
\text { (planned) }\end{array}$ & Oblique & $\approx 68$ & 5 \\
\hline 4 & 366 & Manual & Forward & $\approx 16$ & 22 \\
\hline total & 1,415 & $\begin{array}{c}\text { Planned and } \\
\text { manual }\end{array}$ & various & $68-16$ & 56 \\
\hline
\end{tabular}

Table 2. Details of the performed flights. The time refers only to the effective shooting time and does not consider the other operation required (take off, landing and movements between the different starting points).

\subsection{Terrestrial Laser Scanning: the Faro Focus S120}

The LiDAR survey has been carried out with two ToF TLS, both Faro Focus ${ }^{3 \mathrm{D}} \mathrm{S} 120$ by CAM2 (Figure 3). This kind of device represents a well-consolidated solution and it has been widely adopted for built heritage documentation purposes (Monego et al., 2019). The ranging error of this laser scanner is $\pm 2 \mathrm{~mm}$ in distance measurement and, thanks to embedded camera, it is able to associate a RGB value to point cloud, providing radiometric information (Table 3 ).

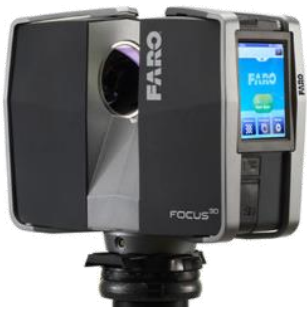

Figure 3. Faro Focus ${ }^{3 \mathrm{D}}$ S 120.

To guarantee metric control of the obtained results, checkerboard registration targets have been placed on vertical surfaces (both inside and outside the building) and measured by total station. The scheme of the scan acquisitions reaches an elevated overlapping between the scans, to facilitate the successive registration operations.

\begin{tabular}{|c|c|}
\hline Specifications & Faro Focus SD $^{\mathbf{S} ~ 120}$ \\
\hline Operational range & $0.6-120 \mathrm{~m}$ \\
\hline Ranging error & $\pm 2 \mathrm{~mm}$ \\
\hline $\begin{array}{c}\text { Vertical/horizontal field of view } \\
\text { (FoV) }\end{array}$ & $305 / 360^{\circ}$ \\
\hline Embedded camera resolution & $70 \mathrm{Mpx}$ \\
\hline Acquisition speed & Up to $976.000 \mathrm{points} / \mathrm{s}$ \\
\hline
\end{tabular}

Table 3. Faro Focus ${ }^{3 \mathrm{D}}$ S 120 principal specifications.

A total amount of 142 scans has been recorded with a quality of $4 \mathrm{x}$ and a resolution of $1 / 5$, corresponding to 1 point every $8 \mathrm{~mm}$ at a distance of $10 \mathrm{~m}$ (Table 4) spending about 4 day for their acquisition

\begin{tabular}{|c|c|c|c|}
\hline $\mathrm{N}^{\circ}$ scans & $\mathrm{N}^{\circ}$ of points $[\mathrm{mln}]$ & Time & $\begin{array}{c}\text { Raw file size } \\
{[\mathrm{MB}]}\end{array}$ \\
\hline mean & 22 & $\approx 12 \mathrm{~min}$ & 113 \\
\hline total & 3,124 & $\approx 28 \mathrm{~h} 30 \mathrm{~min}$ & 16,046 \\
\hline
\end{tabular}

Table 4. TLS scans specifications.

\subsection{Mobile Mapping System: the ZEB-Revo RT}

The ZEB-Revo Real Time (RT) is a MMS based on SLAM algorithm and commercialized by Geoslam. A handheld laser scanner equipped with a RGB camera, connected via Wi-Fi to a tablet and via cable to the processing unit supporting the battery, which are easily wearable as shoulder strap (Figure 4) compose the system.

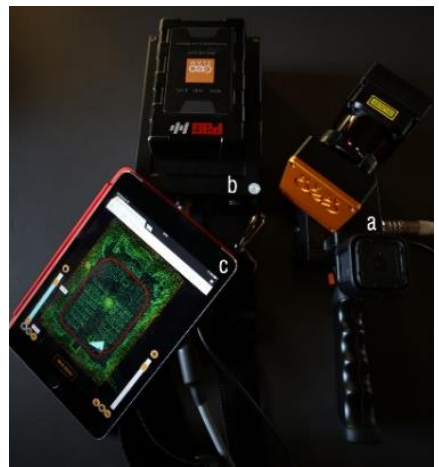

Figure 4. The ZEB-Revo RT system: (a) the handheld device mounting the rotating laser head in the upper part and below the Zeb Cam, (b) the data logger, (c) the tablet connected through Fi-Wi.

SLAM algorithm exploits the 2D time-of-flight laser mounted on a rotating head that progressively extracts range-based profiles and couples them to the position estimated at the same time by an Inertial Measuring Unit (IMU), so the SLAM solves the positioning issue without the use of a GNSS receiver. Moreover, the SLAM exploits the geometry of the surveyed places to assist the estimation of the position given by the IMU. Spaces with high geometrical features are the optimal scenario for the progressive profiles' alignment, enabling to acquire 43200 points/s in a maximum range of $15 \mathrm{~m}$ in outdoor and up to $30 \mathrm{~m}$ in indoor (Table 5) in 30 minutes per scan at most. At the end of each scan acquisition, a point cloud and its associated trajectory are recorded in the data-logger after a pre-processing phase automatically run by the instrument in loco. In a later stage the raw data can be improved through the post-processing phase within the Geoslam Hub software. 


\begin{tabular}{|c|c|}
\hline Specifications & Zeb Revo RT \\
\hline Wavelenght & $905 \mathrm{~nm}$ \\
\hline Laser speed & $100 \mathrm{~Hz}$ \\
\hline Range distance & Up to $30 \mathrm{~m}$ (indoor), $15 \mathrm{~m}$ (outdoor) \\
\hline Laser field of view & $270^{\circ} \times 360^{\circ}$ (horizontal x vertical) \\
\hline Measurement speed & 43,200 points $/ \mathrm{s}$ \\
\hline Laser lines & 100 lines $/ \mathrm{s}$ \\
\hline Points per scan line & 432 \\
\hline Relative accuracy & $3-30 \mathrm{~cm}$ (environment dependent) \\
\hline Weight & $1 \mathrm{~kg}$ (head), $4.1 \mathrm{~kg}$ (carry case) \\
\hline Type of Camera & GoPro Hero Session \\
\hline
\end{tabular}

Table 5. Specification of the Zeb Revo RT.

The ZEB-Revo version constitutes an implementation of the previous Zeb1 and Zebedee, the rotating mechanism and the laser speed are improved, but the integration of a RGB camera, called ZebCam, and the RT tool represent the most interesting evolutions. The dedicated Wi-Fi connect the laser with a tablet enabling to visualize the mapped space in real time, so the operator can control the point cloud elaborated by the ongoing SLAM algorithm step by step. The operator behaviour and steps influence the quality of the results. Some operative guidelines, provided by the company, recommend to: start the acquisition on a planar surface, walk slow in the scenario moving the laser in different directions or following non-linear paths, go around characteristics elements in case of poor geometry environment, pass in slow motion through doorways or when moving from one space to another avoiding changing abruptly the view, and finally finish the scan on a planar surface.

Between the tips suggested by the company and tested in literature (Chiabrando et al., 2019; di Filippo et al., 2018; Sammartano \& Spanò, 2018), performing close loop (starting and ending in the same point) instead of one way solution is the most recommended one. In fact, this strategy assists the SLAM algorithm providing better results in the geometrical reconstruction because inserts the closure between the initial and final phase as constrain. In case of multilevel spaces, horizontal and vertical closed loops along stairs and passageways are suggested to minimize the trajectory drift and need to be planned before the survey, according to the environment configuration. Moreover, it is recommended not to include moving elements in the scene, such as vehicles or people. This strategy is preferable because the SLAM relies on iterative alignment of the recorded profiles, therefore a scene with changing features generates misalignment, while closed, or enclosed spaces with dimensions within the maximum range, highly geometric characteristics, and no moving elements guarantee the highest performance of the ZEB device and the good quality of its results.

Amongst the MMS available on the market, the ZEB-Revo RT constitutes the most appropriate handheld tool in case of articulated and compound architectural structures (di Filippo et al., 2018; Tucci et al., 2018). Its geometric content validation, comparing the Zeb data to a most consolidated and affordable technique as LiDAR one, suggests the Zeb point cloud precision compliant to a scale of 1:100 or 1:200 (Sammartano \& Spanò, 2018). Nonetheless some issues are currently under investigation (Chiabrando et al., 2019). The absolute positioning issue seems to be developing in a stand-alone solution, skipping the alignment phase on a more accurate dataset. In fact, the last Geoslam software release enables to elaborate a .txt file containing the XYZ coordinates of the so called 'reference points'. During the acquisition, standing still for few second on a predetermined point (for example a vertex of a topographic network) allows recording the position of that point in a local coordinates system that refers to the initial point of the scan. These local coordinates can be converted in a global reference system measuring the coordinates of the same points through a GNSS instrument or a traditional total station. The colour of the point cloud remains as added function in the processing phase, in fact the Geoslam Hub allows the optimization of the ZEB point clouds reprocessing the SLAM algorithm with different parameters and giving the possibility to select the 'ZEB-CAM coloured' as one of the types of available colours.

Thanks to SLAM algorithm, portability, and manoeuvrability, the ZEB-Revo RT represents a rapid mapping solution very promising in case of large complexes and uneasy to access spaces, as the Palazzo Ducale. The palace has been completely mapped through multiple scans with the ZEB-Revo RT, exploited both indoor and outdoor to acquire the internal shapes of all the five floors, the cloister and narrow areas. Part of the external walls and portion of the city context formed by difficult to access spaces, such as the narrow streets surrounding the palace and the small area between the entrance of the museum and the facade of the Cathedral. The total volume of about $36.000 \mathrm{~m}^{3}$ was mapped with 15 scans at a mean walking speed of $0.5 \mathrm{~m} / \mathrm{s}$, reaching a total amount of $333 \mathrm{mln}$ of points in about 4 hours and 20 minutes (Table 6). The needed time considers both the effective time of acquisition and the time spending for changing the position and preparing the instrument.

\begin{tabular}{|c|c|c|c|}
\hline Scans & $\begin{array}{c}\mathrm{N}^{\circ} \text { of points } \\
{[\mathrm{mln}]}\end{array}$ & $\begin{array}{c}\text { Time } \\
{[\mathrm{min}]}\end{array}$ & $\begin{array}{c}\text { Raw file size [MB] } \\
\text { Geoslam+ Point cloud preview }\end{array}$ \\
\hline mean & 22 & $\approx 17$ & 91.0 \\
\hline total & 333 & $\approx 260$ & 4,048 \\
\hline
\end{tabular}

Table 6. MMS scans specification.

\section{DATA PROCESSING}

The three datasets were processed separately following the workflow below illustrated.

\subsection{UAV Photogrammetry}

The photogrammetric blocks have been processed with the wellknown SfM-based (Structure from Motion) software Agisoft Photoscan. Images from the first three flights (entire area) have been combined together in a single dataset, while the block of the southwest façade has been considered singularly. During the data processing, the standard workflow has been followed (Ewertowski et al., 2019; Scianna \& La Guardia, 2019). The 12 measured artificial markers have been employed in the Bundle Block Adjustment of planned flights dataset, 8 points as Ground Control Points (GCPs) and 4 as Check Points (CPs) to check the accuracy of the results (Table 7). For the manual flight dataset, 9 checkboard targets placed on the surface of the southwest façade have been used as GCPs and 4 as CPs.

\begin{tabular}{|c|c|c|c|c|c|}
\hline \multicolumn{2}{|c|}{} & \multicolumn{4}{c|}{ RMSE [m] } \\
\cline { 3 - 6 } \multicolumn{2}{|c|}{} & $\mathrm{X}$ & $\mathrm{Y}$ & $\mathrm{Z}$ & Total \\
\hline \multirow{2}{*}{$\begin{array}{c}\text { Flights } \\
\mathrm{n}^{\circ} 1-3\end{array}$} & GCPs & 0.005 & 0.005 & 0.013 & 0.014 \\
\cline { 2 - 6 } & CPs & 0.010 & 0.008 & 0.011 & 0.017 \\
\hline $\begin{array}{c}\text { Flights } \\
\mathrm{n}^{\circ} 4\end{array}$ & GCPs & 0.006 & 0.005 & 0.005 & 0.010 \\
\cline { 2 - 6 } & CPs & 0.008 & 0.006 & 0.005 & 0.011 \\
\hline
\end{tabular}

Table 7. Metric control of the UAV data.

In both cases, because of the photogrammetric process, a dense point cloud has been generated (Figure 5) with a GSD (Ground Sampling Distance) less than $2 \mathrm{~cm}$ for the two point clouds constituted by tens of millions points (Table 8). A 3D TIN 
(Triangular Irregular Network) has been triangulated, an orthophoto of the area and a DMS (Digital Surface Model) have been produced.

\begin{tabular}{|c|c|c|c|c|}
\hline $\begin{array}{c}\text { Flights } \\
\mathrm{n}^{\circ}\end{array}$ & $\begin{array}{c}\mathrm{N}^{\circ} \text { of } \\
\text { images }\end{array}$ & $\begin{array}{c}\text { Extimated GSD } \\
{[\mathrm{cm} / \mathrm{px}]}\end{array}$ & $\begin{array}{c}\mathrm{N}^{\circ} \text { of tie } \\
\text { points }\end{array}$ & $\begin{array}{c}\mathrm{N}^{\circ} \text { of points } \\
\text { of dense cloud }\end{array}$ \\
\hline $1-3$ & 527 & 1.85 & 328,643 & $55,869,452$ \\
\hline 4 & 366 & 0.53 & $1,429,302$ & $37,237,238$ \\
\hline
\end{tabular}

Table 8. Main details of the photogrammetric process.
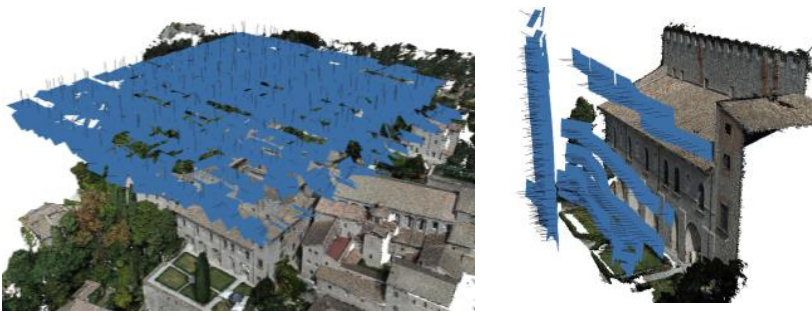

Figure 5. Dense clouds with aligned photos: on the left dataset acquired with the flights 1-3 (planned), on the right the dataset acquired with the flight 4 (manual).

\subsection{Terrestrial Laser Scanner}

Scans have been registered through the Faro SCENE platform using a standard and consolidated workflow (Chiabrando et al., 2016). A first registration is carried out using a procedure based on ICP (Iterative Closest Point) algorithm; subsequently the registered point clouds have been georeferenced through the checkboard targets placed on the vertical surfaces. Because of the complexity of the surveyed spaces, the 142 scans have been divided into 13 macro-areas (depending on the positioning and overlapping of the scans) in order to effectively manage the complete dataset. In Table 9 it is possible to observe the accuracy results after the ICP algorithm and target based procedures.

\begin{tabular}{|c|c|c|c|c|c|}
\hline \multirow{2}{*}{ Block } & \multirow{2}{*}{$\begin{array}{c}\mathrm{N}^{\circ} \text { of } \\
\text { scans }\end{array}$} & $\begin{array}{c}\text { Mean scan } \\
\text { pt tension } \\
{[\mathrm{mm}]}\end{array}$ & $\begin{array}{c}\text { Scan pt } \\
\text { tension < } \\
\mathrm{mm}[\%]\end{array}$ & $\begin{array}{c}\text { Mean } \\
\text { target } \\
\text { tension }\end{array}$ & $\begin{array}{c}\text { St. dev. } \\
\text { Target } \\
\text { tension }\end{array}$ \\
\hline 1 & 10 & 2.09 & 75.9 & 3.75 & 1.43 \\
\hline 2 & 11 & 3.19 & 61.0 & 5.05 & 6.88 \\
\hline 3 & 13 & 2.56 & 67.7 & 4.13 & 2.00 \\
\hline 4 & 8 & 1.63 & 80.3 & 3.72 & 0.22 \\
\hline 5 & 5 & 3.70 & 53.9 & 3.62 & 1.69 \\
\hline 6 & 15 & 1.74 & 77.5 & 3.12 & 1.23 \\
\hline 7 & 3 & 1.43 & 79.2 & 1.51 & 1.18 \\
\hline 8 & 22 & 1.88 & 78.0 & 3.88 & 1.48 \\
\hline 9 & 5 & 1.42 & 89.8 & 3.22 & 1.62 \\
\hline 10 & 13 & 1.42 & 80.7 & 3.52 & 1.50 \\
\hline 11 & 8 & 2.61 & 66.3 & 3.54 & 1.25 \\
\hline 12 & 22 & 1.68 & 78.6 & 3.93 & 1.59 \\
\hline 13 & 5 & 1.60 & 84.3 & 3.16 & 1.50 \\
\hline
\end{tabular}

Table 9. Accuracy results of the LiDAR registration procedures (tension $=$ re-projection discrepancies)

\subsection{Mobile Mapping Systems}

In the processing phase, the Geoslam Hub mainly allows three type of process: 'save results', 'merge' and 'reprocess'. The 'save result' extracts the point clouds with associated trajectories from the raw data, exported from the data-logger. According to the needs, the operator can choose between various format (.e57, .las, .laz, .ply, .txt) with a specific colour that can represent the height along the $\mathrm{z}$ axis, the time of acquisition, shaded representing the ambient occlusions in grey scale, quality of SLAM condition, identification of planar and not-flat surfaces, RGB, RGB with shaded colour for unobserved points. The 'merge' function consists in a first manual alignment of scans, selected by the operator, and an automatic re-computation of the SLAM algorithm considering two or more point clouds that implies a non-rigid roto-translation of the entire dataset in a unique local coordinate system. This process allows the correction of drift errors and misalignment of a scan considering the geometry and trajectory of overlapping scans, but the operator cannot choose the parameters that influence the process. Meanwhile the 'reprocess' function permits to customize the parameters that influence the algorithm and reruns the SLAM algorithm for a single scan. Both these optimization strategies are able to correct the trajectory deviation in single and multi-level spaces (Chiabrando et al., 2019). Moreover, the software allows to visualize and navigate into the 3D point cloud (see Figure 6), very useful for a first check of the obtained results.

For the Palazzo Ducale dataset, after the extraction of the point clouds and their trajectory from the raw data, a first visual analysis was performed to verify the presence of gross errors and misalignment for each scan, through vertical and horizontal sections. Subsequently, the merge function was tested both to correct the misalignment stressed in the previous step and to obtain a unique local coordinate system. A second visual check evaluates the correctness of the merged results. After a manual editing to remove unnecessary objects captured during the survey, the entire Zeb merged point cloud was georeferenced through point-based strategy and ICP alignment to the UAV dataset and evaluated on LiDAR data as partially proposed in recent researches (Chiabrando et al., 2019). Only 12 scans has been processed, obtaining a complete point cloud of $269 \mathrm{mln}$ of points with a file size of about 1 GB (Table 10). In the following section, the results of this methodology are explained.
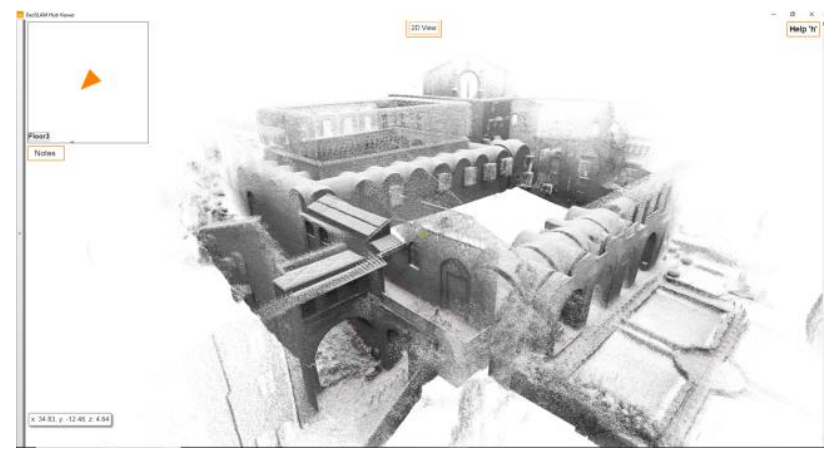

Figure 6. 3D visualisation and navigation through the point cloud within the Geoslam software.

\begin{tabular}{|c|c|c|c|}
\hline Scans & $\begin{array}{c}\mathrm{N}^{\circ} \text { of } \\
\text { points } \\
{[\mathrm{mln}]}\end{array}$ & $\begin{array}{c}\text { Length of } \\
\text { path }[\mathrm{m}]\end{array}$ & $\begin{array}{c}\text { File size }[\mathrm{MB}] \\
\text { Point cloud + trajectory .laz+.txt }\end{array}$ \\
\hline mean & 22 & 311.0 & 91.0 \\
\hline total & 269 & $3,732.2$ & $1,092.3$ \\
\hline
\end{tabular}

Table 10. MMS processed scans specification.

\section{ACHIEVED RESULTS}

The comparison of data derived from different sensors is presented to evaluate the potentialities and drawbacks of each sensor. Some considerations about the employed MMS sensor are firstly considered.

As regards the ZEB dataset, some issues can be stressed, referring to the processing and georeferencing phases. In the 
raw point clouds some gross misalignments appeared. The most relevant is the one reported in the auxiliary room (Figure 7) where the inner volume straddles the external surface of the wall, probably the walking through the passageway was too fast.
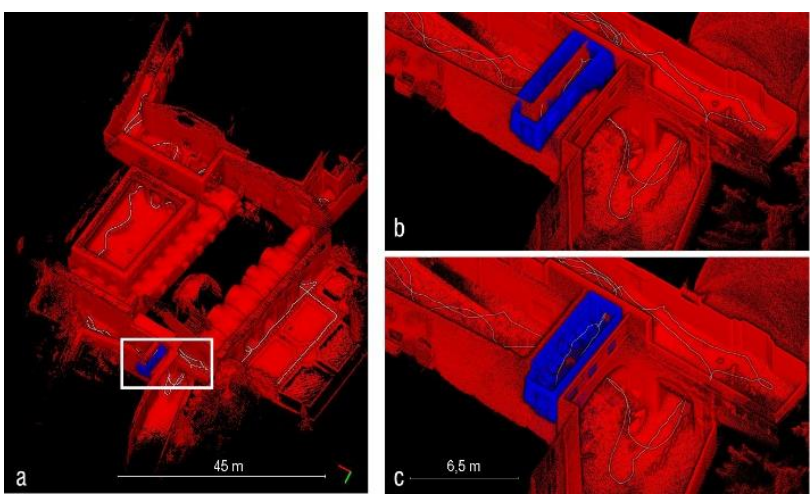

Figure 7. SLAM-based point cloud (red) and its trajectory (white) with highlighted auxiliary room (blue): (a) acquired data, (b) focus on the misalignment of the room in the raw point cloud, (c) data obtained after reprocessing and merge.

A first automatic attempt tried to correct them exploiting the merge function. Nonetheless, some misalignment persisted. The misalignment reported in the auxiliary room, as the other detected, was corrected thanks to the reprocess function that allows customizing some parameters for the SLAM algorithm. In this case, in the global section, the 'convergence threshold' was set to 1 ( 0 by default) and 'rigidity' to -1 ( 0 by default), 'prioritise planar surface' was checked; meanwhile in local section the 'window size' was set to 1 ( 0 by default). The 'convergence threshold' increases the number of iterations and reduces the value considered as limit. Reducing the 'rigidity', the SLAM is more influenced by laser point data and less by IMU data. The 'prioritise planar surface' helps the algorithm to match planar surfaces in the point cloud data. A higher 'window size' value considers a larger sample for each step of calculation. After that, the merge process was carried out to obtain a unique reference system. During the merge process, the uploaded reprocessed point clouds are considered instead of the raw data, so they preserve the geometry corrected before and are globally aligned to the others. The correctness of the alignment is evaluated through Cloud-to-Cloud (C2C) distance of the ZEB data from the reference LiDAR data reporting $2.8 \mathrm{~cm}$ mean error and $2.1 \mathrm{~cm}$ as standard deviation.

The proposed methodology for the geo-referencing process exploits the alignment through UAV dataset and verifies the correctness with the LiDAR as 'ground truth'. The entire Zeb point cloud was aligned to the photogrammetric blocks firstly through 9 points reporting higher values both for mean error and standard deviation than the ICP-like clouds fitting (Table 11). The $\mathrm{C} 2 \mathrm{C}$ distance analysis considering the LiDAR data as reference evaluates the correctness of the ZEB alignment through the Mavic data. In this case the $\mathrm{C} 2 \mathrm{C}$ distance analysis stresses valuable alignment results.

\begin{tabular}{|c|c|c|c|}
\hline \multirow{2}{*}{ Cases } & \multicolumn{2}{|c|}{ MMS-UAV } & MMS-LiDAR \\
\cline { 2 - 4 } & $\begin{array}{c}\text { 9 Points-based } \\
\text { alignment }\end{array}$ & $\begin{array}{c}\text { ICP } \\
\text { alignment }\end{array}$ & $\begin{array}{c}\text { C2C distance } \\
\text { verification }\end{array}$ \\
\hline Mean [cm] & 9.9 & 3.7 & 2.2 \\
\hline st. dev. [cm] & 3.8 & 2.2 & 2.5 \\
\hline
\end{tabular}

Table 11. Results of the ZEB data alignment employing the Mavic data as reference and validation comparing the ZEB aligned data on the LiDAR one.

The merge process represents a powerful solution to improve the profiles alignment of each scan in a global scenario and to automatically obtain the global alignment of the entire dataset, avoiding to calculate it with other software. Nonetheless, no quality report is available, so the operator has to evaluate it, analysing scan by scan, extracting sections for a visual evaluation and aligning the ZEB dataset to another one with known quality. After the tests hereby reported, the following workflow is suggested evaluating the result step by step:

- Extract each raw point cloud and its trajectory

- Merge

- Reprocess scans reporting gross errors (if necessary)

- Merge uploading the reprocessed scans (if necessary)

- Georeference.

By considering the comparison of each system, some parameters are analysed to evaluate the potentialities and drawbacks of each sensor.

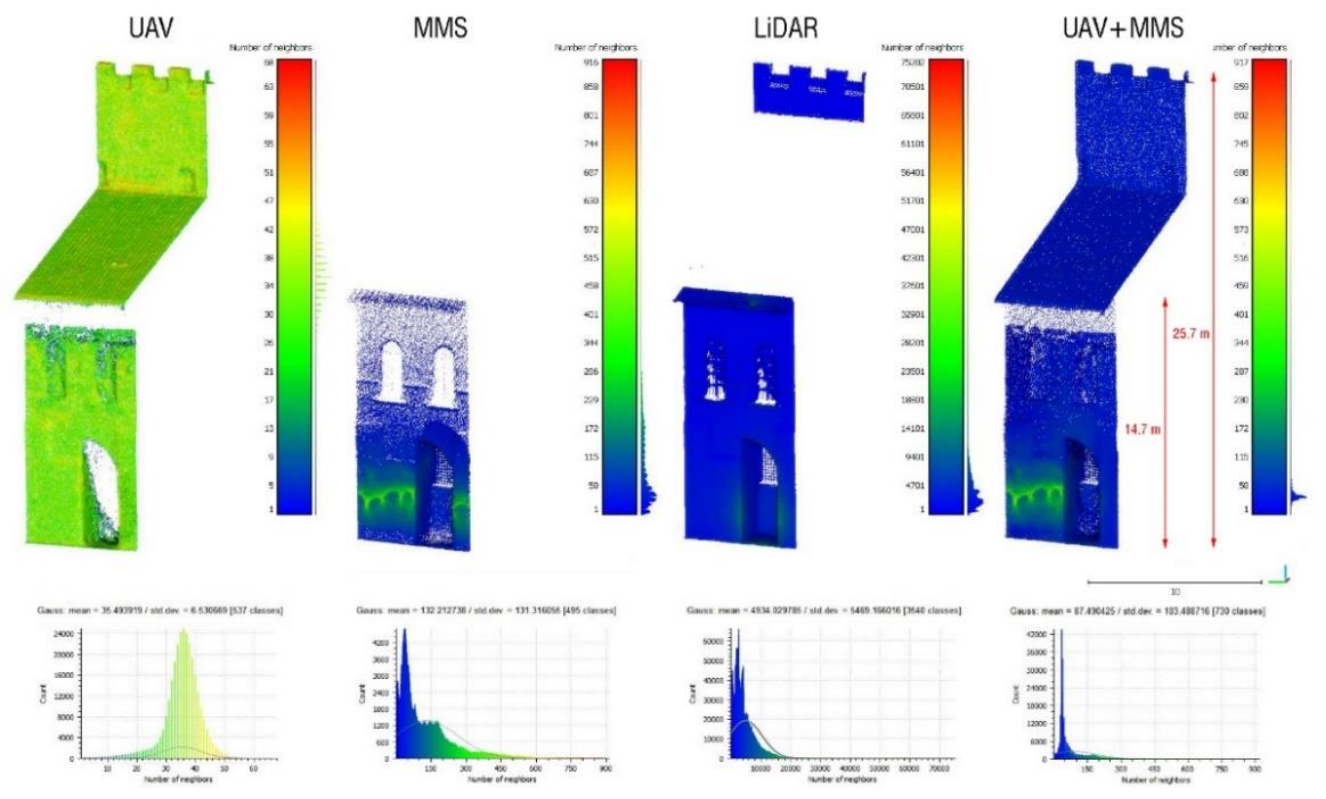

Figure 8. Analysis of the point cloud density for each sensor and for the integration between Mavic Pro and Zeb Revo point clouds. 

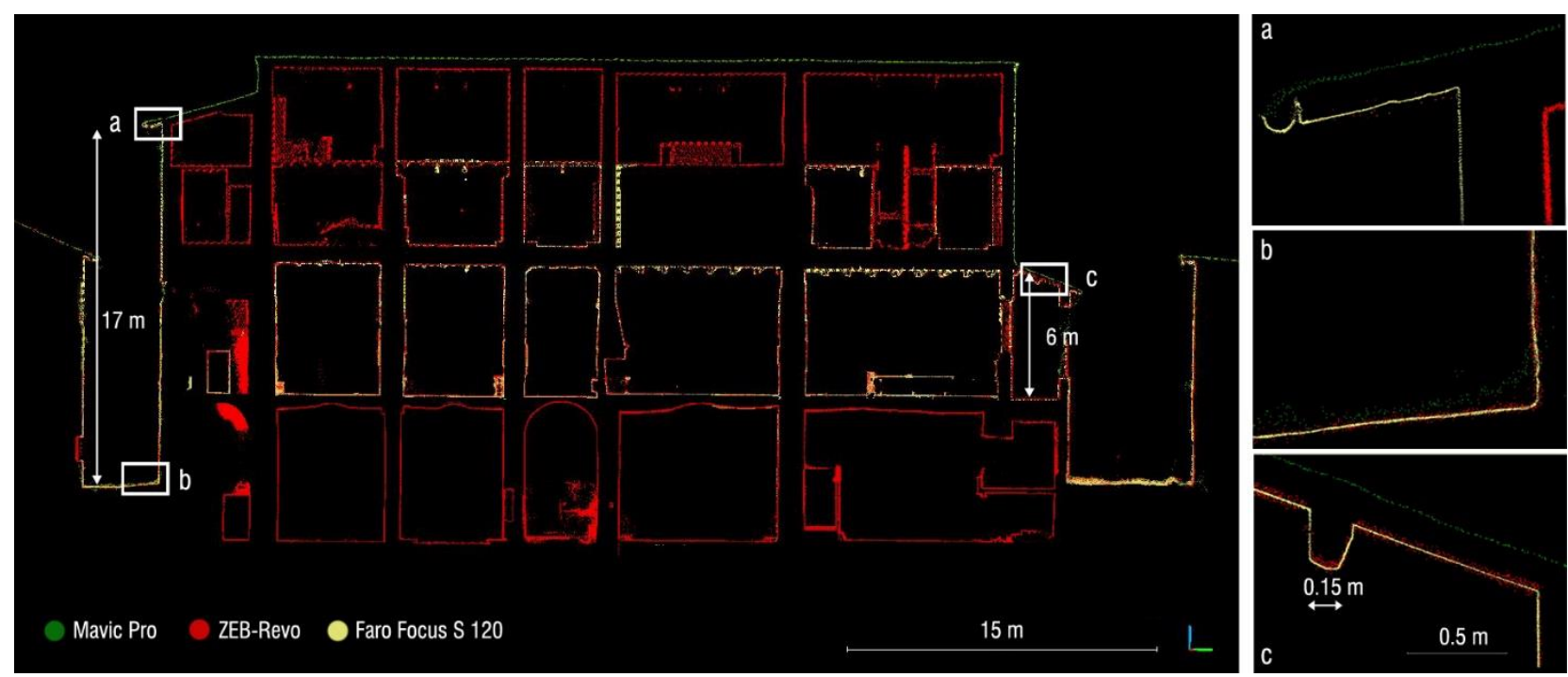

Figure 9. Longitudinal section of the point clouds with focus on three critical points: (a) upper part of the external façade, (b) corners, (c) elements in the ceiling.

The point cloud density of each sensor and of the integration between Mavic Pro and Zeb Revo point clouds is evaluated by considering a portion of the external façade of about 1440 $\mathrm{m}^{2}$ (Errore. L'origine riferimento non è stata trovata.). The number of points and the density mean values (Table 12) of UAV and MMS are quite similar, meanwhile the standard deviation is lower in the UAV because this type of acquisition is more homogeneous along the external surface of the building than the LiDAR and MMS surveys that are confined at the ground floor level.

\begin{tabular}{|c|c|c|c|c|c|}
\hline \multirow{2}{*}{$\begin{array}{c}\text { Point } \\
\text { cloud }\end{array}$} & \multirow{2}{*}{ Data } & \multirow{2}{*}{$\begin{array}{c}\text { Points } \\
{\left[\mathrm{n}^{\circ}\right]}\end{array}$} & \multicolumn{3}{|c|}{$\begin{array}{c}\text { Density [n } \\
\text { sphere radius }=0.1 \mathrm{~m} \text { ] }\end{array}$} \\
\cline { 4 - 6 } & & & mean & st. dev. & $\max$ \\
\hline UAV & $1-3$ flights & 287,581 & 35 & 7 & 68 \\
\hline MMS & 1 scans & 244,983 & 87 & 103 & 917 \\
\hline LiDAR & 7 scans & $12,528,746$ & 4,934 & 5,469 & 75,202 \\
\hline $\begin{array}{l}\text { UAV+ } \\
\text { MMS }\end{array}$ & $\begin{array}{c}1-3 \text { flights } \\
+1 \text { scans }\end{array}$ & 532,564 & 88 & 104 & 917 \\
\hline
\end{tabular}

Table 12. Values of the analysis of point clouds density calculated on a sphere of $10 \mathrm{~cm}$ radius.

By comparing the sensors completeness (Figure 9), it is clear that the Mavic is able to better acquire the upper portions of the building.

Some occlusions are not surveyed, as the wall above the windows (Figure 9a) and in the niche, while it is confirmed that the ZEB cannot achieve an height upper to 15 meters in outdoor, so the LIDAR survey is necessary (thanks to its higher operational range). Meanwhile, as regards the junction between the ground and the building (Figure 9b), the MMS and TLS better survey the corner than UAV. From a terrestrial point of view the MMS can easily capture all the indentations of the building and the inner spaces, also the elements on the ceiling (Figure 9c); TLS approach requires a higher number of scans with an increase of the acquisition time. Referring to the final point clouds (Table 13), different type of survey are compared considering the number of points and their file size also by considering the survey scale. Observing the accuracy of the survey and their scale of restitution, this analysis suggests a good integration between UAV and MMS as complementary rapid mapping sensors.

\begin{tabular}{|c|c|c|c|c|}
\hline $\begin{array}{c}\text { Type of of } \\
\text { survey }\end{array}$ & $\begin{array}{c}\mathrm{N}^{\circ} \text { of points } \\
{[\mathrm{mln}]}\end{array}$ & $\begin{array}{c}\text { File size } \\
\text {.e57 [GB] }\end{array}$ & $\begin{array}{c}\text { Mean and st. } \\
\text { dev. }\end{array}$ & Scale \\
\hline UAV & 90 & 2 & $<2 \mathrm{~cm}$ & $\approx 1: 100$ \\
MMS & 270 & 4 & $2-4 \mathrm{~cm}$ & $\approx 1: 200$ \\
TLS & 3,200 & 70 & $<1 \mathrm{~cm}$ & $\approx 1: 50$ \\
\hline
\end{tabular}

Table 13. Characteristics of the results derived from three different type of survey.

\section{CONCLUSIONS}

In this research datasets acquired by different sensors have been considered and compared, a final analysis (Table 14) considers a global prospective (price, acquisition and processing phases, results). An integrated survey is favourable to provide a complete 3D documentation of built heritage in contexts characterised by elevated complexity. Especially in this context, the MMS tested has proved to be a good and reliable solution for rapid mapping (thanks to its data acquisition rapidity and its versatility) in case of 1:200 survey scale. Moreover, the integration between UAV and MMS seems to be an interesting alternative to the TLS in terms of completeness of the survey and rapidity of acquisition. The obtained model provides up-to-date and geometrical information of the whole palace, giving the possibility to extract $2 \mathrm{D}$ products and integrate other data, such as available historical surveys and stratigraphic analysis; furthermore, by considering the future developments, the 3D model could be considered as a starting point for a realitybased HBIM (Historical Building Information Model) tools.

\section{ACKNOWLEDGEMENTS}

The authors express their gratitude for data acquisition and processing to Filippo Diara, Emilio Abbate and Vittorio Scolamiero from the Laboratory of Geomatics for Cultural Heritage (G4CH) of the Politecnico di Torino - Department of Architecture and Design. A special thanks to Paola Mercurelli Salari, director of Palazzo Ducale of Gubbio, and prof. Francesco Paolo Di Teodoro for their support.

They also declared the PRIN 2015 project as supporter. 


\begin{tabular}{|c|c|c|c|c|c|c|c|c|c|c|}
\hline & \multirow{2}{*}{ Price } & \multicolumn{2}{|c|}{ Acquisition } & \multicolumn{3}{|c|}{ Processing } & \multicolumn{4}{|c|}{ Results } \\
\hline & & Time & $\begin{array}{c}\text { Operator } \\
\text { work }\end{array}$ & Time & $\begin{array}{l}\text { User } \\
\text { work }\end{array}$ & $\begin{array}{c}\text { Hardware } \\
\text { work }\end{array}$ & $\begin{array}{l}\text { Points } \\
\text { density }\end{array}$ & File size & Detail & Completeness \\
\hline $\begin{array}{l}\text { DJI Mavic } \\
\text { Pro }\end{array}$ & & & & & & & & & 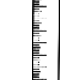 & \\
\hline $\begin{array}{c}\text { ZEB-Revo } \\
\text { RT }\end{array}$ & & & & & & & & $\circ 0$ & E. & \\
\hline $\begin{array}{c}\text { Faro } \\
\text { Focus3D S } \\
120\end{array}$ & & & & & & & & 尚尚 & E. & \\
\hline
\end{tabular}

Table 14. Summary of the employed sensors evaluating different aspects.

\section{REFERENCES}

Capannelli, S., \& Sannipoli, E. A. (2008). Il Palazzo Ducale di Gubbio e Francesco di Giorgio Martini. TMM.

Chiabrando, F., Di Pietra, V., Lingua, A., Maschio, P., Noardo, F., Sammartano, G., \& Spanò, A. (2016). TLS models generation assisted By UAV survey. ISPRS -

International Archives of the Photogrammetry, Remote Sensing and Spatial Information Sciences, XLI-B5(July), 413-420. https://doi.org/10.5194/isprs-archives-XLI-B5413-2016

Chiabrando, F., Sammartano, G., Spanò, A., \& Spreafico, A. (2019). Hybrid 3D Models: When Geomatics Innovations Meet Extensive Built Heritage Complexes. ISPRS International Journal of Geo-Information, 8(3). https://doi.org/10.3390/ijgi8030124

Crommelinck, S., Bennett, R., Gerke, M., Nex, F., Yang, M., \& Vosselman, G. (2016). Review of Automatic Feature Extraction from High-Resolution Optical Sensor Data for UAV-Based Cadastral Mapping. Remote Sensing, 8(8), 689. https://doi.org/10.3390/rs8080689

di Filippo, A., Sánchez-Aparicio, L., Barba, S., MartínJiménez, J., Mora, R., \& González Aguilera, D. (2018). Use of a Wearable Mobile Laser System in Seamless Indoor 3D Mapping of a Complex Historical Site. Remote Sensing, 10(12), 1897. https://doi.org/10.3390/rs10121897

Ewertowski, M., Tomczyk, A., Evans, D., Roberts, D., \& Ewertowski, W. (2019). Operational Framework for Rapid, Very-high Resolution Mapping of Glacial Geomorphology Using Low-cost Unmanned Aerial Vehicles and Structurefrom-Motion Approach. Remote Sensing, 11(1), 65. https://doi.org/10.3390/rs11010065

Hardin, P. J., Lulla, V., Jensen, R. R., \& Jensen, J. R. (2019). Small Unmanned Aerial Systems (sUAS) for environmental remote sensing: challenges and opportunities revisited. GIScience \& Remote Sensing, 56(2), 309-322. https://doi.org/10.1080/15481603.2018.1510088

Lo Brutto, M., Garraffa, A., \& Meli, P. (2014). UAV platforms for cultural heritage survey: first results. ISPRS Annals of Photogrammetry, Remote Sensing and Spatial Information Sciences, II-5, 227-234. https://doi.org/10.5194/isprsannals-II-5-227-2014
Mandelli, A., Fassi, F., Perfetti, L., \& Polari, C. (2017). Testing Different Survey Techniques to Model Architectonic Narrow Spaces. ISPRS - International Archives of the Photogrammetry, Remote Sensing and Spatial Information Sciences, XLII-2/W5, 505-511. https://doi.org/10.5194/isprsarchives-XLII-2-W5-505-2017

Monego, M., Previato, C., Bernardi, L., Menin, A., \& Achilli, V. (2019). Investigating Pompeii: Application of 3D geomatic techniques for the study of the Sarno Baths. Journal of Archaeological Science: Reports, 24, 445-462. https://doi.org/10.1016/j.jasrep.2019.02.009

Sammartano, G., \& Spanò, A. (2018). Point clouds by SLAM-based mobile mapping systems: accuracy and geometric content validation in multisensor survey and standalone acquisition. Applied Geomatics, 10(4), 317-339. https://doi.org/10.1007/s12518-018-0221-7

Sauerbier, M., \& Eisenbeiss, H. (2010). UAVs for the Documentation of Archaeological Excavations. International Archives of Photogrammetry, Remote Sensing and Spatial Information Sciences. Retrieved from http://www.isprs.org/proceedings/xxxvIII/part5/papers/214.p df

Scianna, A., \& La Guardia, M. (2019). Survey and Photogrammetric Restitution of Monumental Complexes: Issues and Solutions-The Case of the Manfredonic Castle of $\begin{array}{lll}\text { Mussomeli. Heritage, 2(1), 774-786. } & \text {. }\end{array}$ https://doi.org/10.3390/heritage2010050

Scolamiero, V. (2019). Il Palazzo Ducale di Gubbio, techniche di rilievo integrate. Politecnico di Torino, Torino. http://webthesis.biblio.polito.it/id/eprint/10108

Tucci, G., Bonora, V., Conti, A., \& Fiorini, L. (2017). Digital Workflow for the Acquisition and Elaboration of 3D Data in a Monumental Complex: the Fortress of Saint John the Babtist in Florence. ISPRS - International Archives of the Photogrammetry, Remote Sensing and Spatial Information Sciences, XLII-2/W5, 679-686. https://doi.org/10.5194/isprsarchives-XLII-2-W5-679-2017

Tucci, G., Visintini, D., Bonora, V., \& Parisi, E. (2018). Examination of Indoor Mobile Mapping Systems in a Diversified Internal/External Test Field. Applied Sciences. https://doi.org/10.3390/app8030401 